\title{
Investigation on lap-joint friction stir welding between AA6351 alloys and DP800 steel sheets
}

\author{
VAN NHAT NGUYEN $^{1}$, QUOC MANH NGUYEN ${ }^{1,2}$, HUONG THAO DANG THI ${ }^{2}$ \\ and SHYH-CHOUR HUANG ${ }^{1, *}$ \\ ${ }^{1}$ Department of Mechanical Engineering, National Kaohsiung University of Applied Sciences, Kaohsiung, \\ Taiwan \\ ${ }^{2}$ Hung Yen University of Technology and Education, Hung Yen, Vietnam \\ e-mail: shuang@cc.kuas.edu.tw
}

MS received 25 October 2017; revised 10 March 2018; accepted 19 March 2018; published online 20 August 2018

\begin{abstract}
With continuous growth and stringent demand for weight reduction in automotive structures, the automotive industry has shown an increasing interest in dissimilar aluminium-steel welding. Dissimilar lap joint between AA6351 alloys of $2 \mathrm{~mm}$ thickness and DP800 advanced high-strength dual-phase steel of $1 \mathrm{~mm}$ thickness has been attempted and joined successfully by friction stir welding with different combinations of parameters. The experimental results of this research work clearly indicate that joining of advanced highstrength steel and aluminium in lap-joint configuration is quite feasible with friction stir welding. Microstructural characterization has been performed by X-ray diffraction (XRD) technique and scanning electron microscopy (SEM). An intermetallic compounds layer was found in the interface of steel and aluminium with thickness of less than $7 \mu \mathrm{m}$ and it was identified as $\mathrm{Al}_{2} \mathrm{Fe}$ and $\mathrm{Al}_{3} \mathrm{Fe}$ by $\mathrm{XRD}$ method. Thermal cycle has been measured and correlated with the microstructure. Shear tensile test has been performed for determining the maximum failure load for different combinations of parameters. Finally, mechanical properties and microstructural observation are correlated with each other.
\end{abstract}

Keywords. Friction stir welding; AA6351 alloys; DP800 steel; IMCs layer; XRD.

\section{Introduction}

Nowadays, energy saving and environmental preservation are the two major concerns in automotive industries. In recent times, higher fuel efficiency is one of the primary targets in automobile and aerospace industries due to increasing fuel prices and strict environmental norms. Introduction of light-weight materials such as aluminium, magnesium alloys into the steel structure has the capability to provide the desired strength and stiffness with high strength to weight ratio to meet the safety regulations. Therefore, in recent times, dissimilar joining is a keen interest for researchers from academia as well as industry. However, the availability of sound joining technique for dissimilar material and particularly for aluminium and steel is difficult to find. However, joining of dissimilar metals by conventional fusion welding techniques is difficult due to large differences in thermophysical properties like melting point, thermal conductivity and thermal expansion, which leads to high distortion, residual stresses and also the formation of a

*For correspondence brittle intermetallic compound (IMC) layer that reduces the joint strength drastically. However, in recent times, a few researchers worked on cold metal transfer (CMT) and successfully performed dissimilar aluminium and steel welding [1,2]. Das et al [1,2] studied the effect of controlled short-circuiting gas metal arc welding of galvannealed steel and aluminium alloy. They observed that with controlled heat input, it can also be possible to control the intermetallic layer thickness and enhance the joint strength. However, solid-state joining technique, like friction welding, has the capability to minimize the formation of intermetallic phases, but this process has some limitations, e.g., one of the joining materials should be circular in shape [3].

Friction stir welding (FSW), which is a solid-state joining process invented by TWI, UK, in 1991, is a promising candidate for joining dissimilar metals [4]. FSW has already been successfully implemented for joining of lowstrength materials like aluminium, magnesium and copper, as well as various refractory alloys. With the success of joining a wide range of materials, FSW has the capability to eliminate or minimize the problems related to dissimilar welding. 
The interface of dissimilar joints produced by FSW is very complicated due to complex deformation and lack of diffusion time. Chen and Kovacevic [5] and Lee et al [6] identified IMCs such as $\mathrm{Fe}_{4} \mathrm{Al}_{13}, \mathrm{Fe}_{2} \mathrm{Al}_{5}$ and $\mathrm{FeAl}_{4}$ at the interface of the friction stir (FS)-welded joint. Fukumoto et al [7] observed an amorphous layer at the interface, while Uzun et al [8] did not identify any IMCs. Whereas, Yilmaz et al [9] reported that due to the increase in IMC layer thickness; fracture was expected to occur at the interface and reducing the tensile strength drastically. Recently, Tanaka et al [10] found that joint strength increased exponentially with a decrease in IMC thickness. Das et al [11] observed a maximum failure load of $\sim 60 \%$ of steel base metal when joining 6063 AA to zinc-coated steel by FSW. Movahedi et al [12] revealed that rotation speed slightly increase the joint strength for FS lap welding of 5083 AA and St-12 alloy sheets. Elrefaey et al [13] studied the effect of tool rotation speed and travel speed of AA 1100-H24 and low-carbon steel lap joint. They noted that breaking load increased with increase in rotation speed [13]. Kimapong and Wanatabe [14] observed increment in tensile shear load of AA 5083/SS 400 joint with decrease in rotational speed and pin depth. However, Chen et al [15] found that welding speed was the predominating factor to determine the tensile properties of the cast aluminium alloy and low-carbon zinc-coated steel joints. Chen and Nakata [16] also studied the effect of the surface condition of steel on joint performance of dissimilar lap joints. Finally they concluded that zinc-coated steel joints showed higher strength than brushed finish and mirror finish steel. In recent times, Kusuda [17] also observed Al-rich $\mathrm{Al}_{13} \mathrm{Fe}_{4}$ phase during FSW of Al-to-steel sub-frame structure. Haghshenas et al [18] studied the FSW-assisted diffusion bonding of 5754 aluminium alloy to coated high-strength steels and observed formation of Al-rich intermetallics. Sorger et al [19] recently studied the overlap joint of AA5754 and DX54 steel using an innovative technique and finally achieved a sound joint. Campanell et al [20] also studied the joint quality and interface characterization of dissimilar lap joints of low-carbon steel-AA6016 aluminium alloy for assemblies in car body parts. Zheng et al [21] studied the dissimilar FSW of AA6061 to 316 stainless steel using $\mathrm{Zn}$ as a filler metal and achieved Al-Zn steel "sandwich" joint. They also concluded that the joint with zinc foil showed better joint strength than that without zinc foil. Leitao et al [22] observed that the use of multi-pass welding increases the bonding area as well as fatigue strength in dissimilar aluminium steel FS lap welding. From this discussion, it is clear that very few works have reported on the FS lap welding of aluminium alloys and automotive advanced high-strength steel (AHSS).

Considering this discussion, the present paper depicts the feasibility study of advanced high-strength dual-phase (DP) 800 steel and AA6351 alloys. Effect of process parameter combination on the formation of the intermetallics and their role in determining the joint strength have been studied extensively. The effect of process parameter on distribution of intermetallics is analysed by X-ray diffraction (XRD) technique and scanning electron microscopy (SEM) with energy-dispersive spectroscopy (EDS).

\section{Materials and method}

The materials used were AA6351 alloys of $2 \mathrm{~mm}$ thickness and advanced high-strength DP 800 steel of $1 \mathrm{~mm}$ thickness. Microstructure of DP 800 and AA6351 alloys base metal microstructure are shown in figure $1 \mathrm{a}$ and $\mathrm{b}$, respectively. The base metals were cut into test specimens of size $145 \mathrm{~mm} \times 100 \mathrm{~mm}$ for lap joint. Schematic of the lap joints is shown in figure 2. A modified milling machine was used for all the FS lap weldings. A H13 high-speed steel tool with shoulder diameter of $11 \mathrm{~mm}$ and pin height of $2 \mathrm{~mm}$ was used for FSW lap joining. Depth of penetration of $2.3 \mathrm{~mm}$ has been used. The tool was tilted by $2^{\circ}$ with the vertical axis in the direction opposite to the welding speed. A dwell time of $1 \mathrm{~s}$ after the complete plunging of the tool pin is maintained for all the experiments. Rotational speeds of 400 and $800 \mathrm{rpm}$ with three different travel speeds 25, 50 and $75 \mathrm{~mm} / \mathrm{min}$ have been selected for dissimilar joining. Transverse tensile specimens were cut from FS-welded lap joint using a CNC cutting machine. The shear tensile test specimen of the lap joints cutting from the lap welded plate is shown in figure 3. The tensile test was performed on a Universal Testing Machine of $50 \mathrm{kN}$ capacity at a cross head speed of $2 \mathrm{~mm} / \mathrm{min}$. The load and displacement histories were simultaneously recorded during the test. The average fracture load value of four specimens was taken for each combination of parameters. The XRD analyses were carried out using the target of $\mathrm{CuK} \alpha$ for identifying intermetallics. Quanta 200 FEG-SEM assisted with EDS facility was used to observe the intermetallic layer and respective chemical composition.

\section{Results and discussion}

Measurement of temperature and thermal cycle is worthwhile to describe the formation of intermetallics, as the formation of intermetallics is a diffusion-controlled phenomenon $[10,15,18]$. During FSW, heat is generated due to the friction between the shoulder and workpiece, and it completely depends on the combination of parameters, i.e., rotational speed and travel speed with respective peak temperature [23, 24]. It clearly indicates that at a constant travel speed, with increasing rotation speed, due to the higher friction between the shoulder and workpiece, more heat is generated at higher rotation speed (figure $4 a$ and b). Maximum temperature measure by the thermocouple is around $325^{\circ} \mathrm{C}$ (figure $4 \mathrm{a}$ ). The measured temperature may 


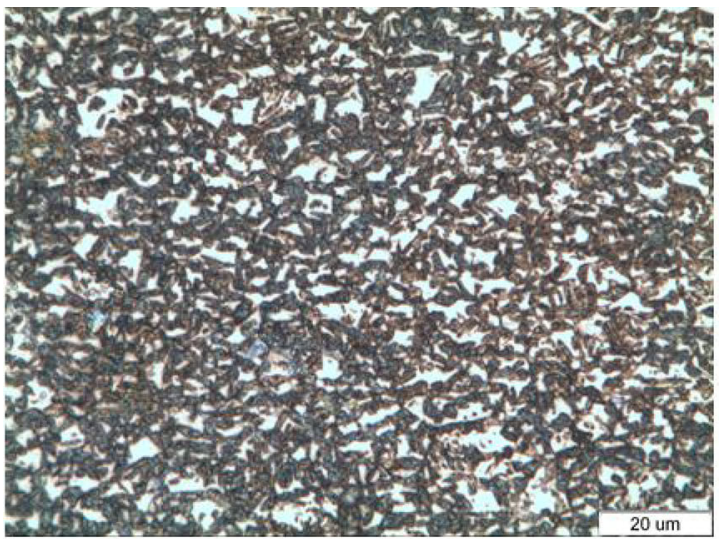

(a)

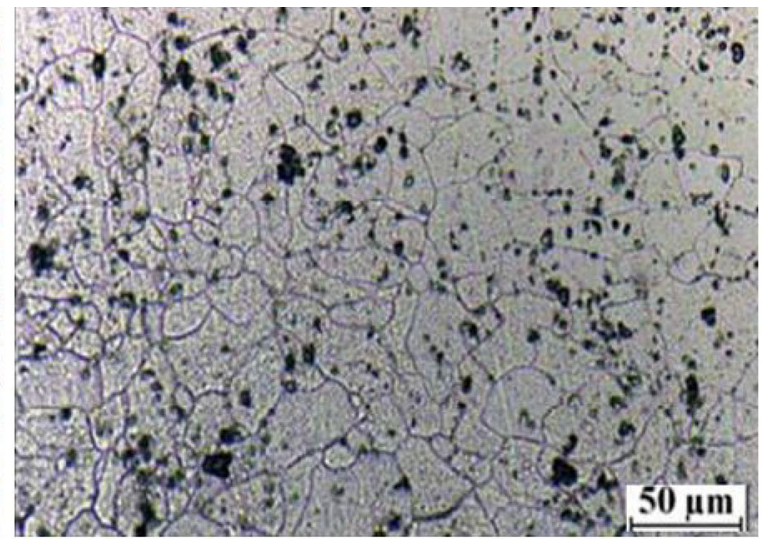

(b)

Figure 1. Base metal microstructure of (a) DP 800 steel and (b) AA6351 alloys.

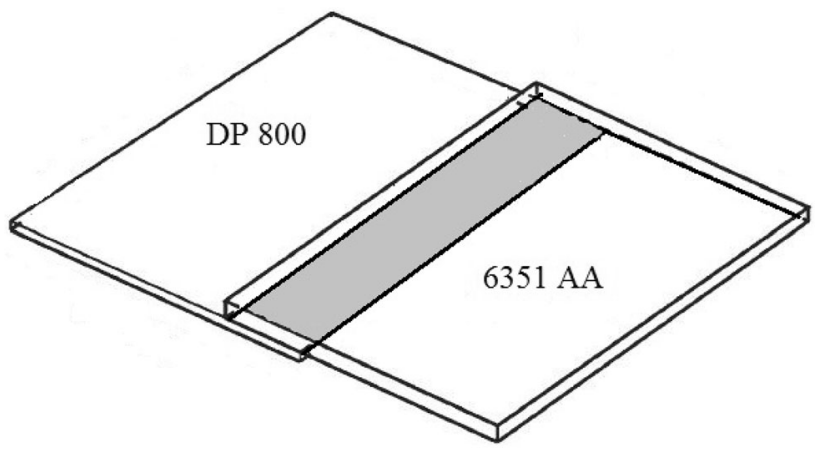

Figure 2. Schematic of the lap joints between DP800 steel and AA6351 alloys by FSW process.

not be exact as there will always be some deviation from the original temperature. However, the thermal cycle will provide some inputs towards the formation of intermetallics.

Load vs. extension curves for 800 and $400 \mathrm{rpm}$ with 3 different travel speeds of 25,50 and $75 \mathrm{~mm} / \mathrm{min}$ combination of parameters are shown in figure $5 a$ and $b$, respectively. It clearly indicates that with increasing travel speed for a constant rpm, failure load decreases for both the cases (figure $5 \mathrm{a}$ and $\mathrm{b}$ ). It is interesting to note that failure load of the joint can reach as high as $4 \mathrm{kN}$. It reveals that the heat input, and respective formation of intermetallics, plays an important role in determining the failure load. It can be noticed that the original interface between the two sheets has been severely disrupted during the shear tensile testing. In other words, interfacial failure is observed for all the tensile specimens.

XRD for all the 6 combinations of parameters has been shown in figure $6 \mathrm{a}-\mathrm{f}$. It can be clearly observed from figure $6 \mathrm{a}-\mathrm{f}$ that the material at all parameter combinations comprises $\mathrm{Al}_{2} \mathrm{Fe}, \mathrm{Al}_{3} \mathrm{Fe}$ and $\mathrm{Fe}_{3} \mathrm{Al}$ type of IMCs. However,

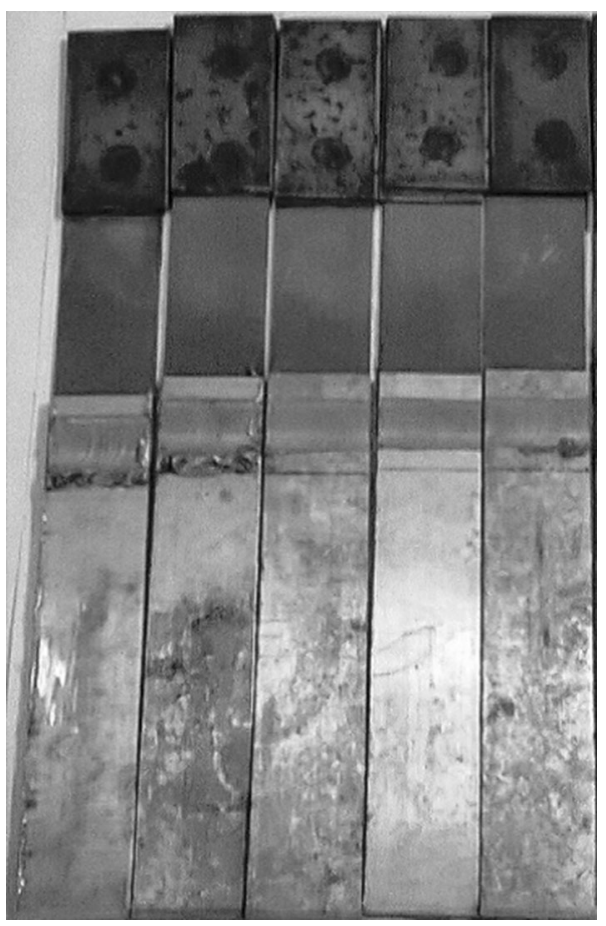

Figure 3. AA6351 alloys and dual-phase 800 steel dissimilar joint and cutting for tensile specimens.

the difference in volume fraction for different combination of parameters can be easily distinguished from the intensity value in the $\mathrm{XRD}$ curves. Interestingly, aluminium-rich intermetallics $\left(\mathrm{Al}_{2} \mathrm{Fe}, \mathrm{Al}_{3} \mathrm{Fe}\right)$ have been formed in higher amount with a small amount of iron-rich intermetallics for all the combinations. Previous researchers also found a similar type of results $[10,15,18]$. The maximum temperature raised around $350{ }^{\circ} \mathrm{C}$, which is higher than the diffusion temperature for aluminium. Hence, it is easier for aluminium to diffuse faster towards the steel rather than the iron particle moving to the aluminium side $[11,15]$. The 

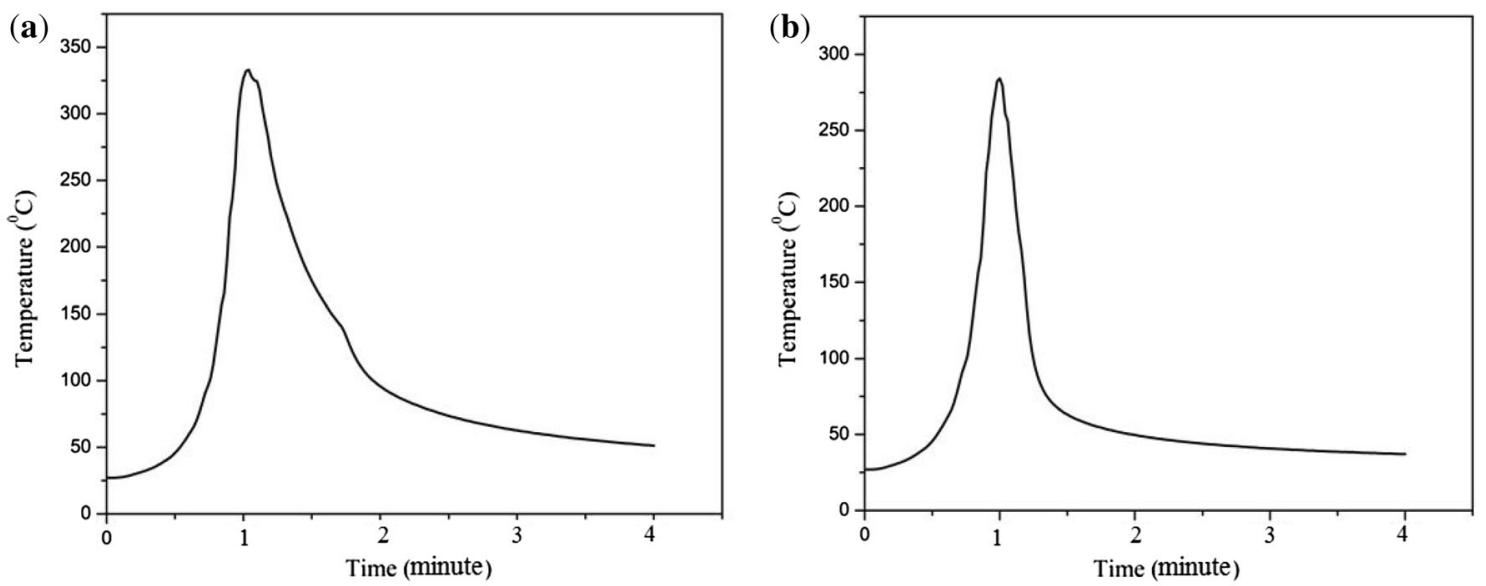

Figure 4. Thermal cycle for (a) $800 \mathrm{rpm} 25 \mathrm{~mm} / \mathrm{min}$ and (b) $800 \mathrm{rpm} 50 \mathrm{~mm} / \mathrm{min}$ combination of parameters.

\section{parameter}


Figure 5. Load vs. extension curve for dissimilar lap welding.

diffusion temperature for steel is quite higher than that of aluminium in the diffusion process; this makes it more difficult for iron particles to move towards aluminium. It is noted that the material at $800 \mathrm{rpm}$ and $25 \mathrm{~mm} / \mathrm{min}$ combination of parameters is richer in intermetallics, which can be qualitatively explained from the XRD curves. At the higher rotational speed of $800 \mathrm{rpm}$ and $25 \mathrm{~mm} / \mathrm{min}$ combination of parameters, both the temperature and heat input are higher compared with the $400 \mathrm{rpm}$ and $25 \mathrm{~mm} / \mathrm{min}$ combination of parameters, leading to lower cooling rate. Moreover, lower cooling rate enhances the formation and growth of the intermetallics in case of $800 \mathrm{rpm}$ and $25 \mathrm{~mm} / \mathrm{min}$ combination.

The $800 \mathrm{rpm}$ and $25 \mathrm{~mm} / \mathrm{min}$ combination of parameters with lower cooling rate shows thicker and more homogeneous distribution of intermetallic layer (figure 7a). However, due to lower heat input in case of $400 \mathrm{rpm}$ and $25 \mathrm{~mm} / \mathrm{min}$ combination of parameters the growth is not homogeneous as clearly revealed from figure $7 \mathrm{~b}$. The observation is a strong indication that peak temperature, as well as cooling rate, plays the predominating role not only for formation of intermetallics but also for determining the joint failure load. Average intermetallic thickness for $800 \mathrm{rpm} 25 \mathrm{~mm} / \mathrm{min}$ and $400 \mathrm{rpm} 25 \mathrm{~mm} / \mathrm{min}$ is $\sim 7.8$ and $\sim 4.3 \mu \mathrm{m}$, respectively. Figure 8 shows the variation of IMC thickness with combination of process parameters. It clearly indicates that heat input generated due to the process has a direct effect on the IMC thickness. Effect of heat input on the determination of IMC thickness is also observed by a few researchers $[15,16,21]$. The $800 \mathrm{rpm}$ and $25 \mathrm{~mm} / \mathrm{min}$ combination of parameters with homogeneous distribution of intermetallics throughout the interface restricts the crack growth during shear tensile test, which is attributed to higher joint strength. Intimate contact between the two surfaces via intermetallics and the intermetallics thickness are the important factors during shear tensile test. It should be noted that if the bond at the interface is not in firm contact, sudden failure will take place for the $400 \mathrm{rpm}$ 

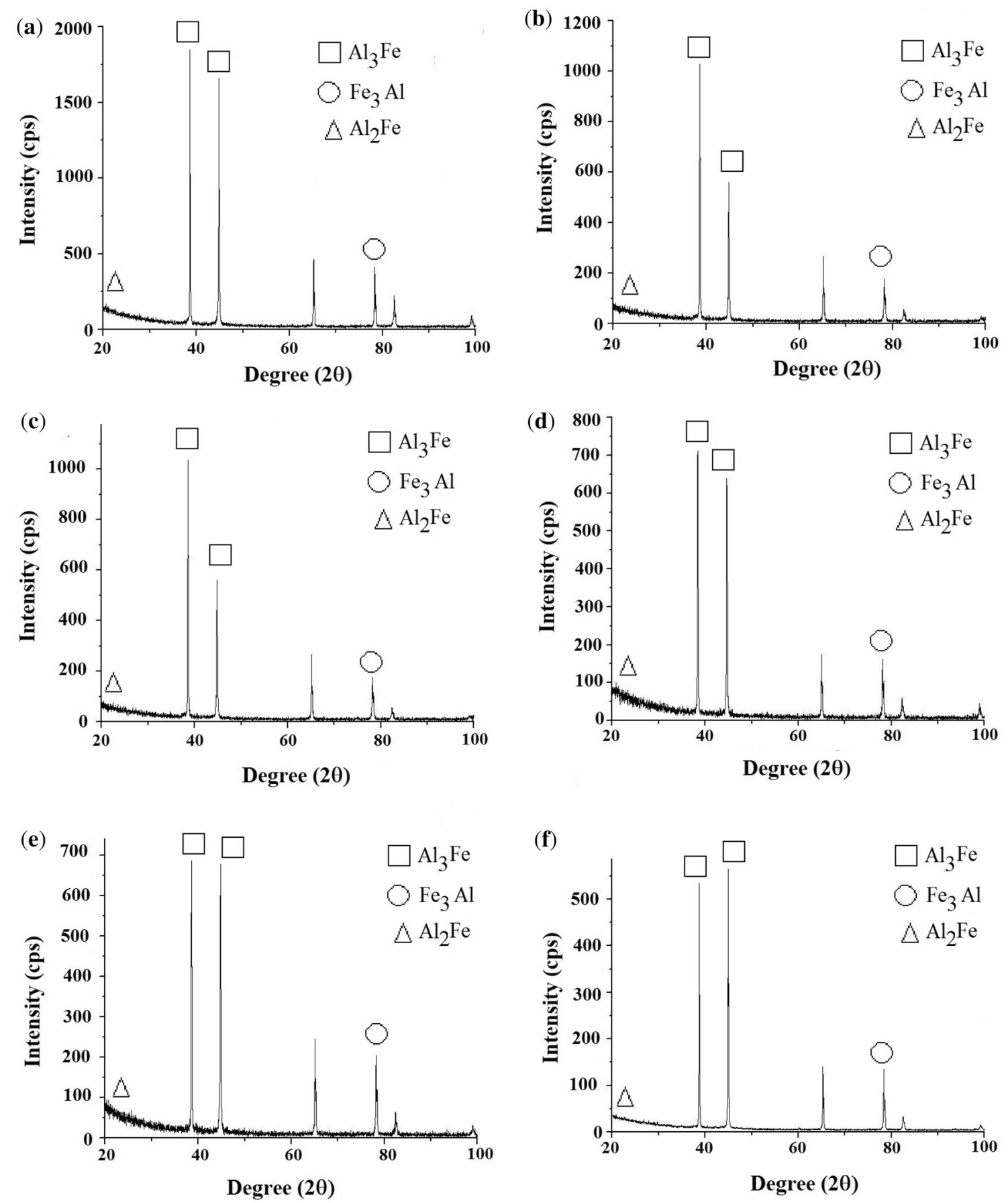

Figure 6. X-ray diffraction pattern for (a) $800 \mathrm{rpm} 25 \mathrm{~mm} / \mathrm{min}$, (b) $800 \mathrm{rpm} 50 \mathrm{~mm} / \mathrm{min}$, (c) $800 \mathrm{rpm} 75 \mathrm{~mm} / \mathrm{min}$, (d) $400 \mathrm{rpm}$ $25 \mathrm{~mm} / \mathrm{min}$, (e) $400 \mathrm{rpm} 50 \mathrm{~mm} / \mathrm{min}$ and (f) $400 \mathrm{rpm}, 75 \mathrm{~mm} / \mathrm{min}$ combination of parameters.

combinations. This is the reason why shear strength decreases with increasing higher travel speed from 25 to 50 and $75 \mathrm{~mm} / \mathrm{min}$ at a constant rotational speed.

Lower heat input leads to higher cooling rate and restricts the growth of intermetallics formation as well as decreases the intermetallics thickness (figure 8). Consequently, a minimum thickness of intermetallics is necessary, because if there is not enough thickness and volume fraction of intermetallics, fracture is more possible because of a sudden transition at the interface between aluminium alloys and steel sheet [11, 25, 26].

Moreover, due to very high area fraction of IMC, sometimes microcracks would be long enough to propagate under low stress. Hence, it can be concluded that good joint strength between aluminium and steel is achieved within a certain range of heat input. This is the reason why 

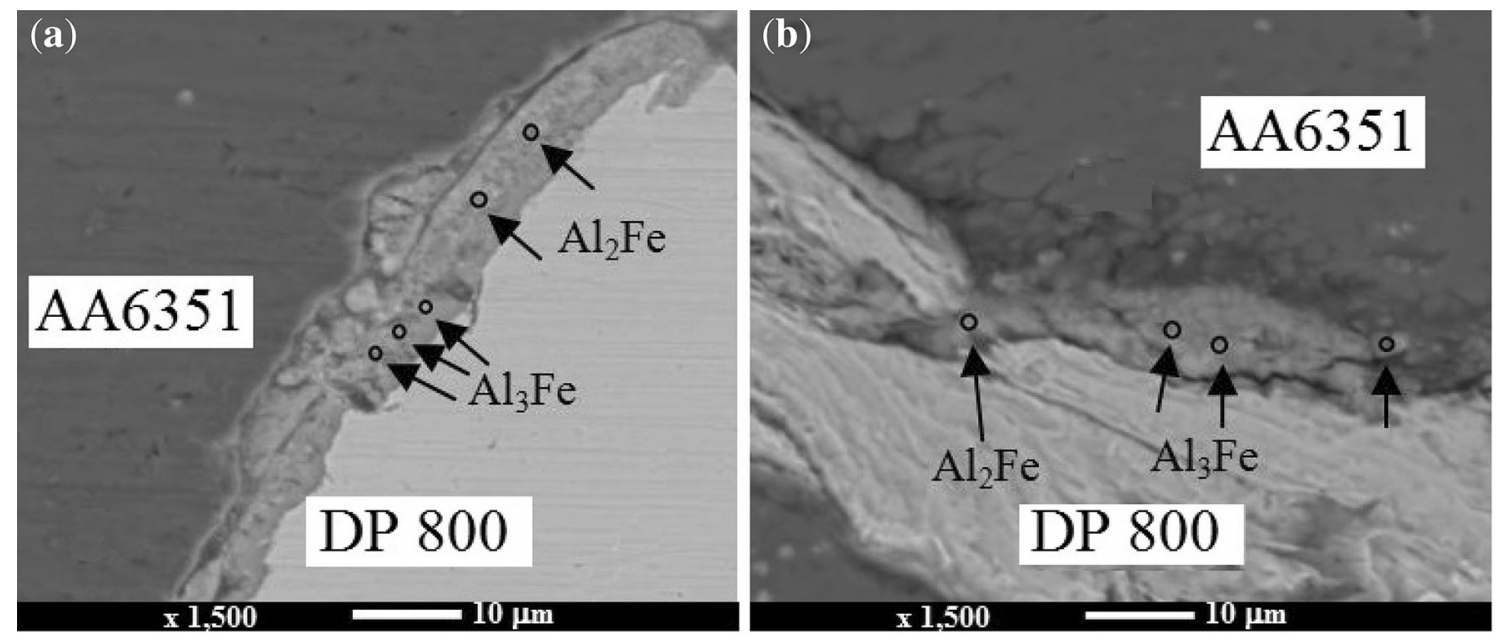

Figure 7. SEM image of intermetallics at the interface for (a) $800 \mathrm{rpm} 25 \mathrm{~mm} / \mathrm{min}$ and (b) $400 \mathrm{rpm} 25 \mathrm{~mm} / \mathrm{min} \mathrm{combination} \mathrm{of}$ parameters.

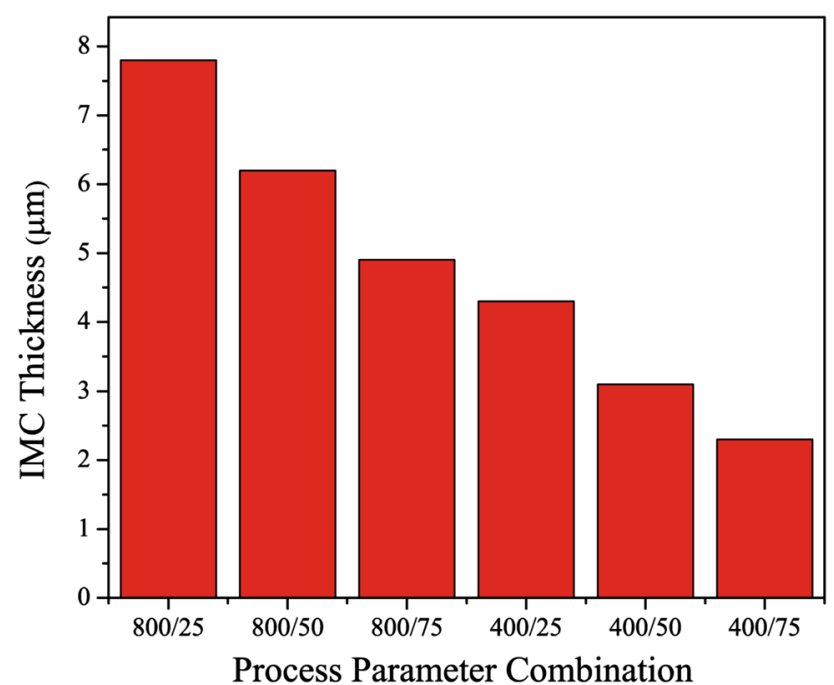

Figure 8. Variation of IMC thickness with process parameter combination. parameter optimization is very important for this study. Quasi-brittle-type failure is observed after shear tension for both steel and aluminium sides as shown in figure $9 \mathrm{a}$ and $\mathrm{b}$, respectively, in case of $800 \mathrm{rpm}$ and $25 \mathrm{~mm} / \mathrm{min}$ combination of parameters.

\section{Conclusions}

Lap welding of dissimilar material AA6351 alloys and advanced high-strength DP 800 steel with dissimilar thickness enabled their successful joining by FSW process.

In this present study, $800 \mathrm{rpm}$ and $25 \mathrm{~mm} / \mathrm{min}$ travel speed combination of parameters is the optimized one with maximum failure load of $4 \mathrm{kN}$.

Higher intermetallic thickness of $\sim 7.8 \mu \mathrm{m}$ with high volume fraction of Intermetallics for $800 \mathrm{rpm} 25 \mathrm{~mm} / \mathrm{min}$ combination of parameters shows higher failure load. It
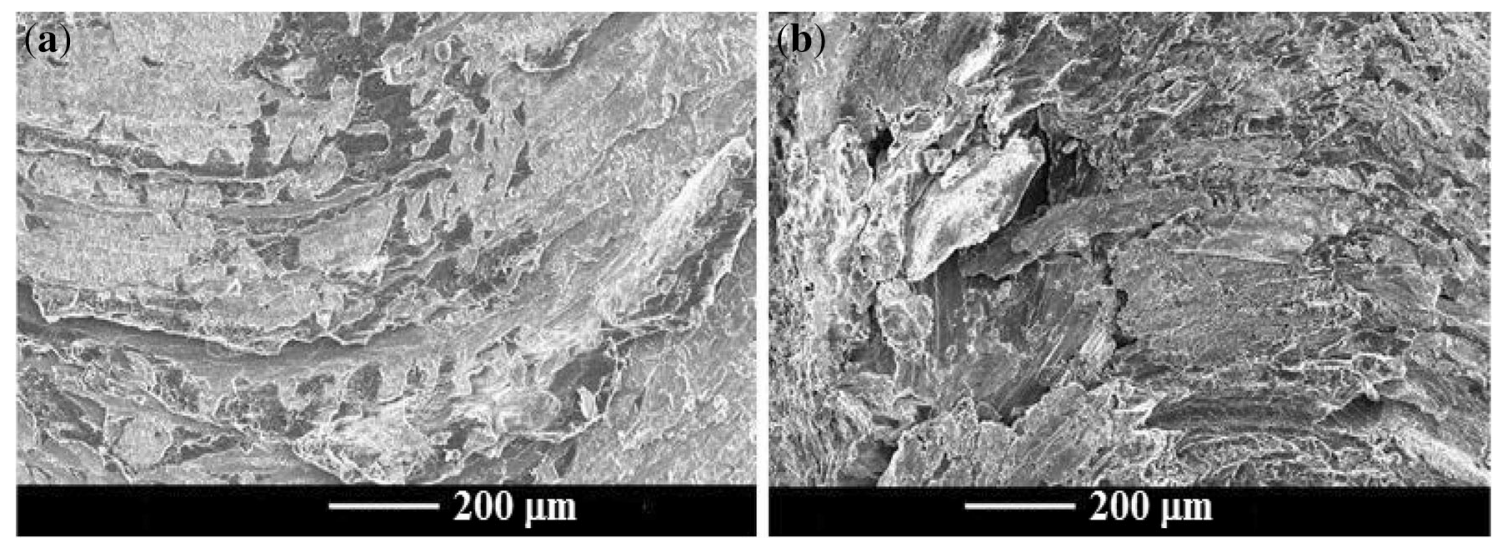

Figure 9. SEM image of fracture surface after shear tension: (a) steel side and (b) aluminium side. 
indicates that joint strength is strongly dependent on the thickness of intermetallics at the aluminium-steel interface.

Interfacial failure has been observed during shear tensile testing for all the combinations of parameters.

Aluminium-rich intermetallics has been formed in higher volume fraction at the interface than that of iron-rich intermetallics for all combinations of parameters.

\section{Acknowledgements}

This research was supported by a project under Grant number B2018-SKH-05 and Center for Research and Applications in Science and Technology, Hung Yen University of Technology and Education, under Grant number UTEHY.T031.P1718.02.

\section{References}

[1] Das A, Shome M, Goecke S F and De A 2017 Joining of aluminium alloy and galvanized steel using a controlled gas metal arc process. J. Manuf. Process. 27: 179-187

[2] Das A, Shome M, Das C R, Goecke S F and De A 2015 Joining of galvannealed steel and aluminium alloy using controlled short circuiting gas metal arc welding process. Sci. Technol. Weld. Join. 20(5): 402-408

[3] Aritoshi M and Okita K 2002 Friction welding of dissimilar metals. J. Japan Weld. Soc. 71(6): 432-436

[4] Thomas W M, Nicholas E D, Needham J C, Murch M G, Templesmith P and Dawes C J 1991 Improvements to friction welding. GB Patent Application No. 9125978.8

[5] Chen C M and Kovacevic R 2004 Joining of Al 6061 alloy to AISI 1018 steel by combined effects of fusion and solid state welding. Int. J. Mach. Tool. Manuf. 44(11): 1205-1214

[6] Lee W B, Schmuecker M, Mercardo U A, Biallas G and Jung S B 2006 Interfacial reaction in steel-aluminum joints made by friction stir welding. Scr. Mater. 55(4): 355-358

[7] Fukumoto S, Tsubakino H, Okita K, Aritoshi M and Tomita T 2000 Amorphization by friction welding between 5052 aluminum alloy and 304 stainless steel. Scr. Mater. 42(8): 807-812

[8] Uzun H, Donne C D, Argagnotto A, Ghidini T and Gambaro C 2005 Friction stir welding of dissimilar Al 6013-T4 to X5CrNi18-10 stainless steel. Mater. Des. 26(1): 41-46

[9] Ylmaz M, Col M and Acet M 2002 Interface properties of aluminum-steel friction-welded components. Mater. Charact. 49(5): 421-429

[10] Tanaka T, Morishige T and Hirata T 2009 Comprehensive analysis of joint strength for dissimilar friction stir welds of mild steel to aluminum alloys. Scr. Mater. 61(7): 756-759

[11] Das H, Basak S, Das G and Pal T K 2013 Influence of energy induced from processing parameters on the mechanical properties of friction stir welded lap joint of aluminum to coated steel sheet. Int. J. Adv. Manuf. Technol. 64(9-12): $1653-1661$
[12] Movahedi M, Kokabi A H, Reihani S M S, Cheng M J and Wang C J 2013 Effect of annealing treatment on joint strength of aluminum-steel friction stir lap weld. Mater. Des. 44: 487-492

[13] Elrefaey A, Takahashi M and Ikeuchi K 2005 Application of friction stir welding to lap joint of aluminum to steel. In: Proceedings of the National Meeting of JWS, p. 132

[14] Kimapong K and Wanatabe T 2005 Lap joint of A5083 aluminum alloy and SS400 steel by friction stir welding. Mater. Trans. 46(4): 835-841

[15] Chen Y C, Komazaki T, Kim Y G, Tsumura T and Nakata K 2007 Effect of the surface state of steel on the microstructure and mechanical properties of dissimilar metal lap joints of aluminum and steel by friction stir welding. In: Proceedings of the International Welding/Joining Conference, pp. 435-436

[16] Chen Y C and Nakata K 2008 Effect of the surface state of steel on the microstructure and mechanical properties of dissimilar metal lap joints of aluminum and steel by friction stir welding. Metall. Mater Trans. A 39: 1985-1992

[17] Kusuda Y 2013 Honda develops robotized FSW technology to weld steel and aluminum and applied it to a mass-production vehicle. Ind. Robot: Int. J. 40(3): 208-212

[18] Haghshenas M, Abdel-Gwad A, Omran A M, Gökçe B, Sahraeinejad S and Gerlich A P 2014 Friction stir weld assisted diffusion bonding of 5754 aluminum alloy to coated high strength steels. Mater. Des. 55: 442-449

[19] Sorger G, Wang H, Vilacal P and Santos T G 2017 FSW of aluminum AA5754 to steel DX54 with innovative overlap joint. Weld. World 61(2): 257-268

[20] Campanell D, Spena P R, Buffa1 G and Fratini L 2016 Dissimilar Al-steel friction stir welding lap joints for automotive applications. In: Proceedings of the 19th International ESAFORM Conference on Material Forming, vol. 1769, pp. 100005-1-100005-6

[21] Zheng Q, Feng X, Shen Y, Huang G and Zhao P 2016 Dissimilar friction stir welding of $6061 \mathrm{Al}$ to 316 stainless steel using $\mathrm{Zn}$ as a filler metal. J. Alloys Compd. 686: 693-701

[22] Leitao C, Arruti E, Aldanondo and E Rodrigues D M 2016 Aluminium-steel lap joining by multipass friction stir welding. Mater. Des. 106: 153-160

[23] Zimmer S, Langlois L, Laye J and Bigot R 2010 Experimental investigation of the influence of the FSW plunge processing parameters on the maximum generated force and torque. Int. J. Adv. Manuf. Technol. 47(1-4): 2011-2015

[24] Mehta M, Arora A, De A and Debroy T 2011 Tool geometry for friction stir welding-optimum shoulder diameter. $M e$ tall. Mater. Trans. A 42A(9): 2716-2722

[25] Khandkar M Z H, Khan J A and Reynolds A P 2003 Prediction of temperature distribution and thermal history during friction stir welding: input torque based model. Sci. Technol. Weld. Join. 8(3): 165-174

[26] Santella M, Grant G and Arbegast W 2003 Plunge testing to evaluate tool materials for friction stir welding of $6061+20$ wt $\% \mathrm{Al}_{2} \mathrm{O}_{3}$ composite. In: Proceedings of the 4th International Symposium on Friction Stir Welding 